\title{
Cold metal transfer welding of AA1050 aluminum thin sheets
}

\author{
Alaattin Ozan İrizalp ${ }^{1}$, Hülya Durmuş ${ }^{2}$ \\ Nilay Yüksel ${ }^{2}$, İlyas Türkmen ${ }^{2}$
}

\author{
${ }^{1}$ Celal Bayar University, Institute of Natural and Applied Sciences, Manisa, Turkey \\ e-mail: ozan@canozanpano.com.tr \\ ${ }^{2}$ Celal Bayar University, Faculty of Engineering, Materials Engineering Department, Manisa, Turkey \\ e-mail:hulya.durmus@cbu.edu.tr; nilay.yuksel@cbu.edu.tr; ilyas.turkmen@cbu.edu.tr
}

\begin{abstract}
This study was aimed to investigate the welding parameters on mechanical behavior of 2 mm thick AA1050 sheet materials joined by cold metal transfer (CMT) method. Macro structural examination showed that decreasing heat input decreased the pore size in the weld metal. Tensile test was applied and failure occurred in heat affected zone of aluminum sheet metal. Maximum tensile strength was found in the sample with minimum heat input. Heat affected zone was observed explicitly in the sample produced with the maximum heat input. Decreasing joint gap affected the bending strength positively. Bending strength was found superior with maximum bonding line length.
\end{abstract}

Keywords: CMT welding, mechanical characterization, AA1050.

\section{INTRODUCTION}

Arc welding of thin sheet aluminum alloys pose unique challenges. Due to comparatively high coefficients of thermal expansion and thermal conductivity when compared to steel, control of heat input to the weldments is a major prerequisite to avoid some problems such as burning through and distortion [1,2]. The benefits including thin heat affected zone, little distortion and improved productivity made the cold metal transferring (CMT) process incomparable when applied in welding thin plates and weld-brazing [3].

Cold metal transfer (CMT) is an automated welding process based on dip transfer welding, characterized by controlled material deposition during the short circuit of the wire electrode to the work piece [4]. This arc welding process is reported for working with a lower heat input compared to other arc processes. The consequences are less base metal impaired, low deformation and low residual stress level in assembly [5]. In the conventional dip arc process the wire is moved forward until a short circuit occurs. In the CMT process the wire is not only pushed towards but also drawn back from the work piece [6]. The wire movement occurs with high frequency - an oscillating wire feeding with an average oscillation frequency up to $70 \mathrm{~Hz}$ is used [6,7]. In CMT, the term "cold" has to be understood in terms of a welding process, but when set against the conventional MIG/MAG process, CMT is still a cold process that constantly alternates between hot and cold phases. During the arcing period, the filler metal is moved towards the weld pool.

When the filler metal dips into the weld-pool, the arc is extinguished and the welding current is lowered. The backward movement of the wire assists droplet detachment during the short circuit and the short circuit current is kept small [6]. Transfer of the filler metal to the welding pool takes place without applied voltage and current [7]. Finally, the wire motion is reversed and the process begins all over again [6].

Although the process relies on a filler wire short circuit for material transfer, by controlling both the cycle arcing phase and the wire feed rate sufficient energy can be realized to melt both the base material and a molten globule of filler wire. The result is that material transfer can be realized at the point of short circuit with low arc energy and hence reduced heat input to the weldments [2].

Güngör et al [6] performed the similar and dissimilar weld joints of 5083 and 6082 aluminum alloys and reported that similar CMT weld joints exhibited better fatigue performance in comparison with dissimilar weld of aluminum alloys. 
Feng et al [1] joined pure aluminum thin sheets effectively by CMT short-circuiting metal transfer and reported that the low heat input of CMT can decrease the deflection deformation of the thin sheets.

High purity aluminum alloys are used widely in low-strength corrosion resistant vessels and tanks [8]. In literature, CMT welding was applied mostly to join dissimilar materials such as aluminum to galvanized steel $[9,10,11]$, aluminium to magnesium [12,13], titanium to copper [14]. This study was aimed to investigate the effect of welding parameters on mechanical properties of AA1050 thin sheet materials welded by CMT method.

\section{MATERIALS AND METHODS}

In the present study, similar overlap welding of $2 \mathrm{~mm}$ thick 1050 aluminum alloy were carried out by CMT welding under argon shielding gas (Table 1) using aluminum based filler welding wire. AA1050 sheet material was cut to $250 \times 100 \mathrm{~mm}^{2}$ in size for welding process. Chemical composition of AA1050 was given in Table 2.

Table 1: Welding parameters

\begin{tabular}{l|l|l|l}
\hline Sample & A & B & C \\
\hline Voltage & $17.5 \mathrm{~V}$ & $17.7 \mathrm{~V}$ & $18.2 \mathrm{~V}$ \\
\hline Current & $107 \mathrm{~A}$ & $112 \mathrm{~A}$ & $121 \mathrm{~A}$ \\
\hline Wire feeding rate (m/min) & 4.8 & 5 & 5.8 \\
\hline Welding speed (m/min) & 1.5 & 1.5 & 2 \\
\hline
\end{tabular}

Table 2: Typical chemical composition of AA1050

\begin{tabular}{l|l|l|l|l|l|l}
\hline $\mathbf{A l}$ & $\mathbf{C u}$ & $\mathbf{F e}$ & $\mathbf{S i}$ & $\mathbf{Z n}$ & $\mathbf{M n}$ & $\mathbf{T i}$ \\
\hline 99.5 & 0.05 & 0.40 & 0.25 & 0.05 & 0.05 & 0.05 \\
\hline
\end{tabular}

\subsection{Macrostructural and Microstructural Investigation}

Macrostructural investigations were carried out by Nikon SMZ 1000 stereo microscope to observe the porosity of the weld metal.

Cut and molded samples were polished and etched with Keller's reagent for microstructural investigation. Heat affected zone and weld metal were observed by Nikon LV100 optical microscope using Clemex software.

\subsection{Hardness Test}

Vickers hardness test was applied according to ASTM: E-384 by EMCO Test Hardness Tester under $1 \mathrm{~kg}$ load and 10 seconds along the parent metal-weld zone-parent metal order.

\subsection{Tensile and Three Point Bending Tests}

Mechanical strength of specimens was determined by Shimadzu tensile testing device with a rate of 1 $\mathrm{mm} / \mathrm{min}$ at room temperature. Tensile test was applied according to EN ISO 4136:2012.

Three point bending test was executed according to EN ISO 5173 at room temperature with a rate of $2 \mathrm{~mm} / \mathrm{min}$

\section{RESULTS AND DISCUSSION}

\subsection{Heat Input}

As is known heat input has a significant effect on properties of weldment. Also Weman [15] reported that the heat input has great importance for the rate of cooling of the weld. It can be calculated from the Equation (1) [15]: 
Where $\mathrm{Q}=$ heat input $(\mathrm{kJ} / \mathrm{mm})$

$\mathrm{U}=$ voltage $(\mathrm{V})$

$\mathrm{I}=$ current $(\mathrm{A})$

$\mathrm{V}=$ welding speed $(\mathrm{mm} / \mathrm{min})$

Efficiency is known as the heat transfer rate to the work piece, and is given 0.90 for MIG/MAG welding $[15,16]$. CMT method was defined as modified MIG welding before. Therefore the efficiency value was assumed 0.90 for present study. Heat input of weldments were calculated according to these and given in Table 3.

Table 3: Heat input of welded samples.

\begin{tabular}{l|l}
\hline Sample & Heat input (J/mm) \\
\hline $\mathrm{A}$ & 74.9 \\
\hline $\mathrm{B}$ & 79.3 \\
\hline $\mathrm{C}$ & 66.1 \\
\hline
\end{tabular}

\subsection{Macrostructural and Microstructural Investigation}

Macrostructural investigations revealed the formation of pores in weld metal. According to literature findings, the reasons of porosity in weld metal of aluminium alloys are the entrapment of the shielding gas in the molten pool and hydrogen, which has high solubility in molten aluminium but very low solubility in the solid $[8,17]$. Porosity in aluminium weld originates from entrapped gases within the weld puddle. Contaminants in the shielding gas, air, and water as well as contaminants in the base or filler metals can be the origin of these gases [18].

Weld cooling rate substantially affects the volume of porosity retained in a gas-contaminated weld. At fast cooling rates, the level of porosity is low, as the nucleation and growth of bubbles in the liquid are severely suppressed. Similarly, at very slow cooling rates, porosity is minimal because bubbles have ample time to coalesce, float, and escape from the weld pool. At intermediate cooling rates, the greatest volume of porosity in a weld is observed, as conditions are optimum for both formation and entrapment of virtually all of the evolved gases in the weld [19]. Based on this information, it can be told that Sample A and Sample B showed an intermediate cooling rate due to the large pores almost at the weld bead surface which could not pull away from the weld. Sample C cooled and solidified faster by virtue of low heat input and avoid the pores to become larger.

Gulshan et al [18] studied on the weld joint of 1xxx series aluminium alloy by TIG method and found that for higher heat input porosity was the minimum in quantity. According to their reports, this may be attributed to the fact that as heat input increases during welding; solidification process slows down, decreasing the formation of porosity. However Norris et al [20] applied Nd:YAG laser welding to join 304L austenitic stainless steel and found out that pore size increases with increasing heat input. They offer to keep heat input low and penetration efficiency high to minimize weld porosity. Larger pores were observed in higher heat inputs in present study. Lowering heat input minimized the pore size; however porosity of the weld metal did not reduced significantly. As is seen from Figure 1, pores located near the exterior surface of weld bead in higher heat inputs so slower cooling rates as small pores distributed even in the middle zone of weld metal in Sample $\mathrm{C}$ produced with minimum heat input and faster cooling rate. 

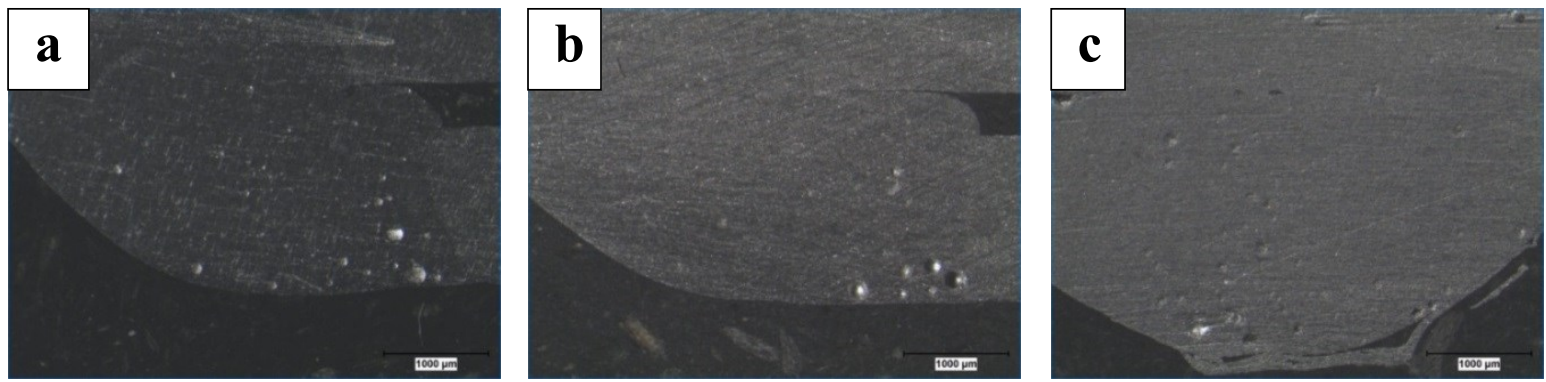

Figure 1: Pores in the weld metal of : a) Sample A; b) Sample B; c) Sample C

Decreasing the gap between the aluminium sheets affected the fusion positively (Figure 2 and Figure 3). Although Sample $C$ produced with the minimum heat input, longer bonded line length was found in this sample (Figure 3c) which has the minimum joint gap (Figure 2c). It was thought that fusion occurred even without the filler material because the gap between the metal sheets was less enough to provide both heat and mass transfer easily.
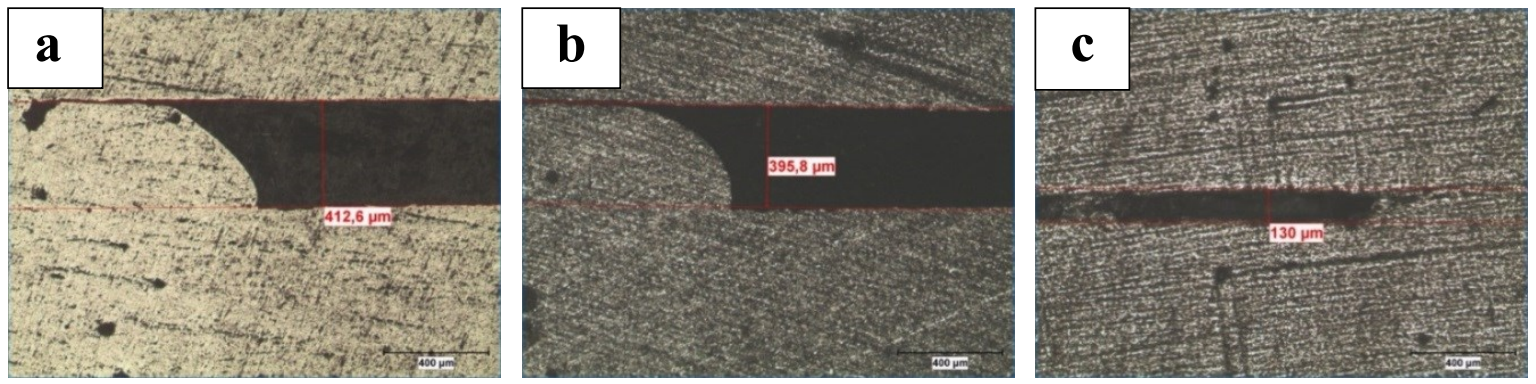

Figure 2: Joint gap: a) Sample A; b) Sample B; c) Sample C
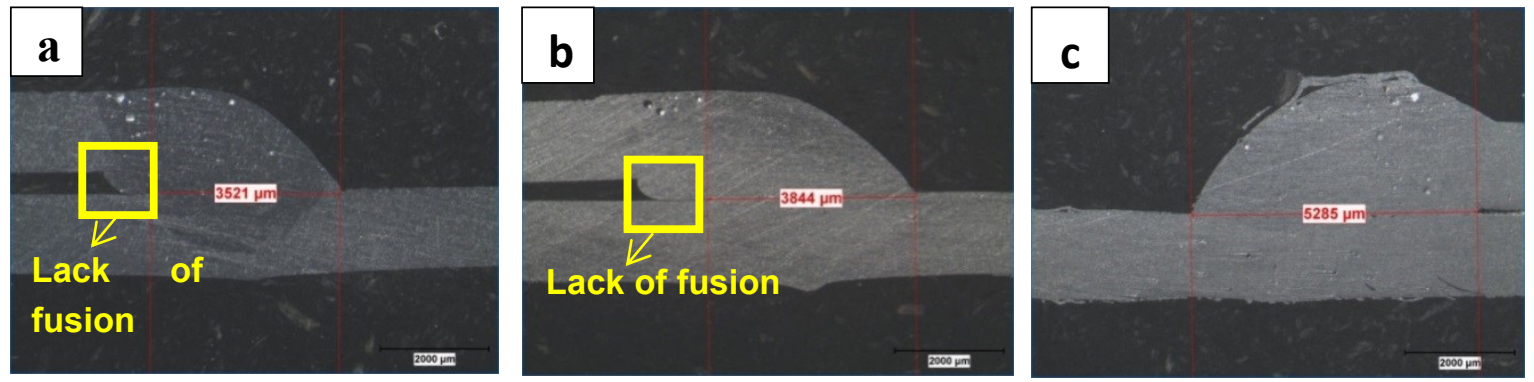

Figure 3: Bonded line length of a) Sample A; b) Sample B; c) Sample C

Chen et al [21] studied on the effect of joint gap on the performance of laser overlap welded joints of galvanized steel and concluded that a sufficient joint gap is necessary to allow the removal of vapored zinc. According to their work, if there was smaller or no joint gap, welding defects, such as spatters and pores and soon, would be generated due to the vapored zinc. On the contrary, the two sheets couldn't be melted together when the joint gap was bigger than the limit joint gap. Lack of fusion was observed in Sample A and Sample B and this was attributed to the larger joint gap. However lack of fusion was not observed in Sample C which possesses the minimum joint gap and the superior joining.

Weld metal of samples consisted of equiaxial grains as is seen from Figure 4a. Also recrystallization led to the grain growth which was observed in HAZ as expected (Figure 4b). Directional grain growth occurred at the base metal/weld metal interface due to the heat flow (Figure $4 \mathrm{~b}$ ). 


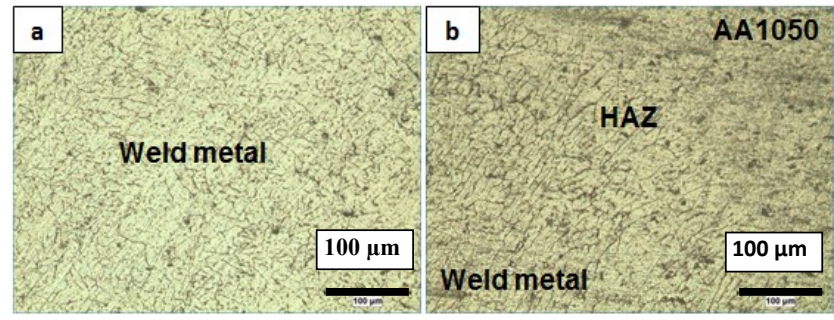

Figure 4: a) Weld metal and, b) heat affected zone of Sample A

\subsection{Hardness Test}

A loss of strength is often encountered in the heat affected zone (HAZ) of weldments due to grain growth during welding [8]. Hardness surveys of samples have proved the existence of HAZ in all samples as is seen from the hardness traverse of samples (Figure 5, Figure 6 and Figure 7). So failure was expected to be occurred in HAZ during tensile testing. Maximum hardness value of weld metal was observed in Sample C (Figure 7). Maximum hardness of weld metal was determined in Sample $\mathrm{C}$ which was attributed to the lower heat input.

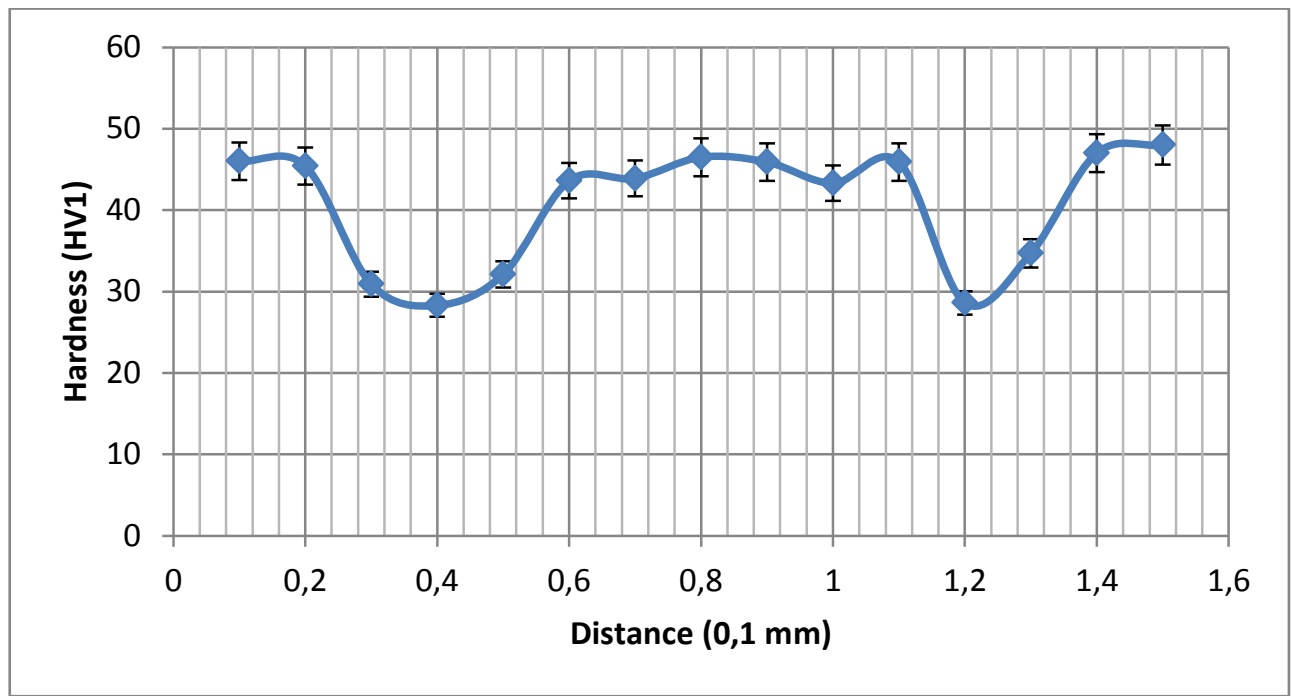

Figure 5: Hardness traverse across the weld metal and base materials of Sample A

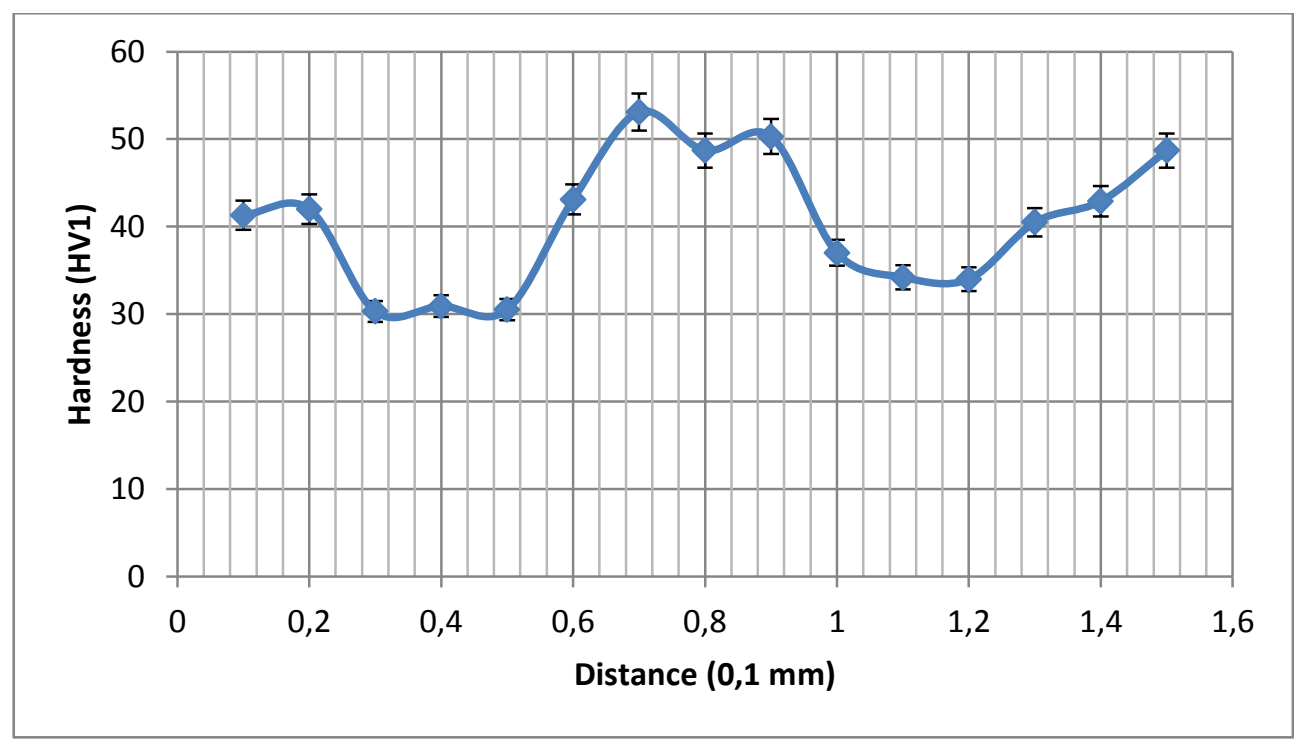

Figure 6: Hardness traverse across the weld metal and base materials of Sample B 


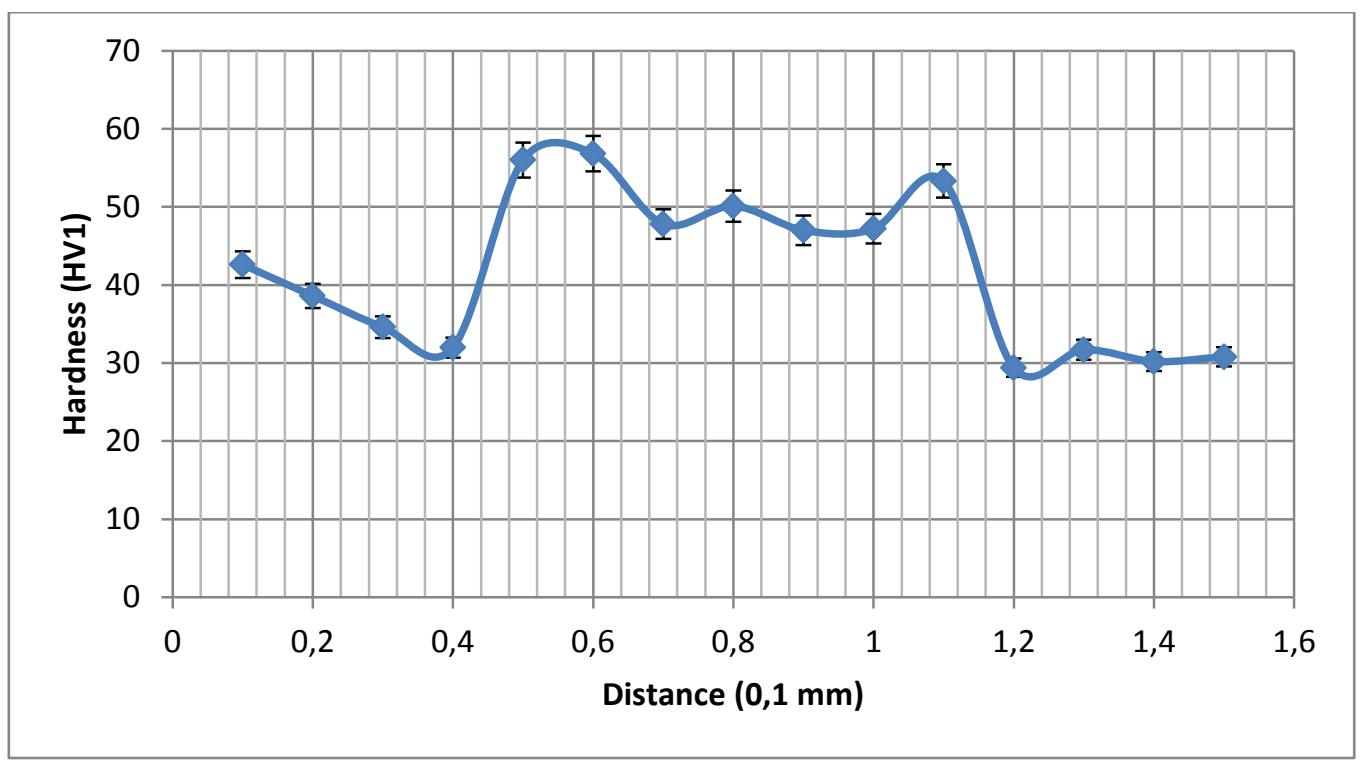

Figure 7: Hardness traverse across the weld metal and base materials of Sample C

\subsection{Tensile Test}

Tensile testing results of CMT welded samples were given in Figure 8. As a result of tensile testing, failure of all samples was observed in HAZ of aluminium base material. As is seen from Figure 8, tensile strength of aluminium sheet material was found greater than that of welded structures. This finding indicated the existence of HAZ for all samples.

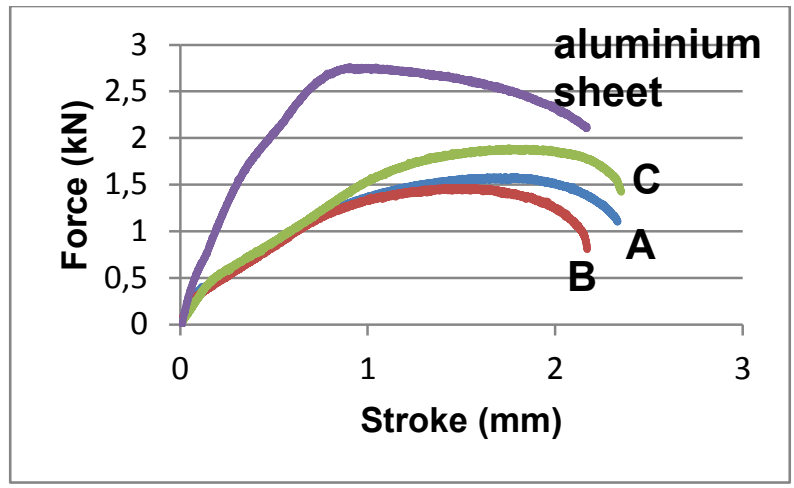

Figure 8: Force-stroke curves of welded samples and aluminium sheet base material

The weld strength of aluminium alloys increases as the heat input per unit length of the weld per unit thickness of the work piece decreases [16]. Fast cooling leads to a finer macrostructure, usually to a less coarse microstructure, higher hardness and greater strength [22]. The heat input should be minimized to provide fast cooling and higher weld strength. Due to its lower heat input, Sample C exhibited better mechanical properties than other samples.

\subsection{Three Point Bending test}

Three point bending test revealed that increasing bonding line length increased the bending strength. As might be expected, load-bearing weld area increased with increasing bonding line length, so bending strength was improved. Sample $\mathrm{C}$ showed the maximum bending strength. Although the tensile strength of Sample A was found superior to Sample C, Sample A exhibited worse bending strength as compared to Sample C (Figure 9). 


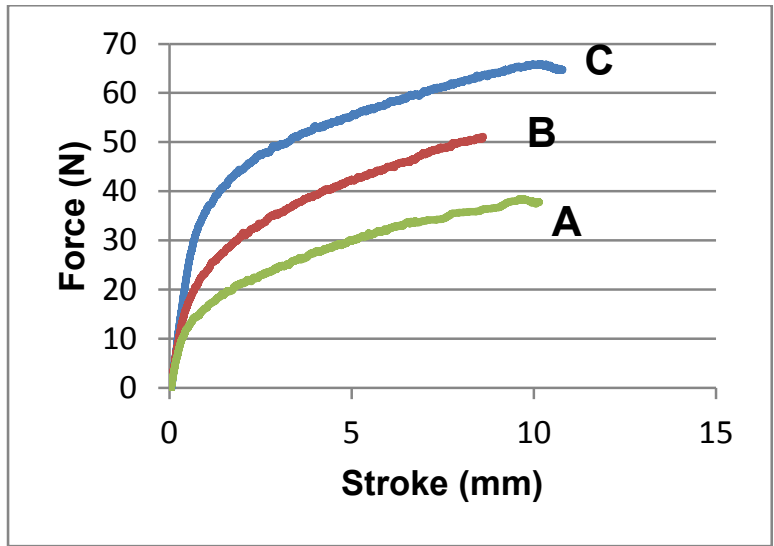

Figure 9: Bending strength of samples

Consequently it was understood that the bending strength was not affected by heat input, it responded the bonding line length in other words fusion performance instead.

\section{CONCLUSIONS}

Present study revealed that CMT welding method achieved to join $2 \mathrm{~mm}$ thick AA1050 aluminum alloy due to its low heat input feature. Burning through problem was not observed although the welded sheets are thin. Also, reducing heat input retarded the recrystallization of cold rolled aluminium sheet during the welding process, hence maximum tensile strength and hardness were observed in sample with minimum heat input. Besides, at higher heat input, pores were located near the exterior surface of weld metal. However pores became smaller and distributed overall the weld metal at lower heat input due to the fast cooling rate which suppressed the formation and coalescence of pores.

Based on the examination the effect of joint gap on mechanical properties, it was observed that decreasing the joint gap increased the fusion performance so the bonding line of weld metal. Increasing bonding line length increased the bending strength. Failure occurred in all samples at heat affected zone after tensile test. Tensile strength was found independent of joint gap. Heat input affected the heat affected zone so the tensile strength. However, bending strength was affected by the bonding line length.

\section{BIBLIOGRAPHY}

[1] FENG, J., ZHANG, H., HE, P. "The CMT short-circuiting metal transfer process and its use in thin aluminium sheets welding”, Materials \& Design, v. 30, pp. 1850-1852, May 2009

[2] PICKIN, C. G., WILLIAMS, S. W., LUNT, M. "Characterisation of the cold metal transfer (CMT) process and its application for low dilution cladding”, Journal of Materials Processing Technology, v. 211, n. 3, pp. 496-502, Mar 2011

[3] SHU, F., LV, Y., LIU, Y., et al., "Residual stress modeling of narrow gap welded joint of aluminum alloy by cold metal transferring procedure", Construction and Building Materials, v. 54, pp. 224-235, 2014

[4] PICKIN, C. G., YOUNG, K. "Evaluation of cold metal transfer (CMT) process for welding aluminium alloy”, Sci Technol Weld Joi, v. 11, n. 5, pp. 583-585, 2006

[5] BENOIT, A., JOBEZ, S., PAILlARD, P., et al., "Study of Inconel 718 weldability using MIG CMT process", Science and Technology of Welding and Joining, v. 16, n. 6, pp. 477-482, Aug 2011

[6] GUNGOR, B., KALUC, E., TABAN, E., et al., "Mechanical and microstructural properties of robotic Cold Metal Transfer (CMT) welded 5083-H111 and 6082-T651 aluminum alloys", Materials \& Design, v. 54, pp. 207-211, Feb 2014

[7] TALALAEV, R., VEINTHAL, R., LAANSOO, A., et al., "Cold metal transfer (CMT) welding of thin sheet metal products", Estonian Journal of Engineering, v. 18, n. 3, pp. 243-250, 2012

[8] MATERS, G. The welding of aluminium and its alloys, 1 ed., England, Cambridge, Woodhead Publishing Limited, 2002

[9] CAO, R., HUANG, Q., CHEN, J. H., et al, "Cold metal transfer spot plug welding of AA6061-T6-togalvanized steel for automotive applications", Journal of Alloys and Compounds, v. 585, pp. 622-632, Feb 
2014

[10] CAO, R., YU, G., CHEN, J. H., et al., "Cold metal transfer joining aluminum alloys-to-galvanized mild steel”, Journal of Materials Processing Technology, v. 213, n. 10, pp. 1753-1763, Oct 2013

[11] ZHANG, H. T., FENG, J. C., HE, P., et al., "The arc characteristics and metal transfer behaviour of cold metal transfer and its use in joining aluminium to zinc-coated steel", Materials Science and Engineering: A, v. 499, n. 1-2, pp. 111-113, Jan 2009

[12] CAO, R., WEN, B. F., CHEN, J. H., et al., "Cold Metal Transfer joining of magnesium AZ31B-toaluminum A6061-T6”, Materials Science and Engineering: A, v. 560, pp. 256-266, Jan 2013

[13] JING, S., KEHONG, W., QI, Z., et al., "Microstructure Characteristics and Properties of Mg/Al Dissimilar Metals Made by Cold Metal Transfer Welding with ER4043 Filler Metal", Rare Metal Materials and Engineering, v. 42, n. 7, pp. 1337-1341, Jul 2013

[14] CAO, R., FENG, Z., CHEN, J. H. "Microstructures and properties of titanium - copper lap welded joints by cold metal transfer technology", Materials \& Design, v. 53, pp. 192-201, Jan 2014

[15] WEMAN, K.. Welding processes handbook, 1 ed., Cambridge England, Woodhead Publishing Limited, 2003

[16] KOU, S. Welding Metallurgy, 2 ed., Hoboken, New Jersey, USA, John Wiley \& Sons, Inc.,Publication, 2002.

[17] YANG, S., ZHANG, J., LIAN, J., et al, "Welding of aluminum alloy to zinc coated steel by cold metal transfer", Materials \& Design, v. 49, pp. 602-612, Aug 2013

[18] GULSHAN, F., AHSAN, Q. "Effect of Heat Input on The Structure And Properties of Aluminium Weldment", Iranian Journal of Materials Science \& Engineering, v. 10, n. 2, pp. 11-18, Jun 2013

[19] LAMPMAN, S., Weld Integrity and Performance, 1. ed., USA, ASM International, Materials Park, 1997

[20] NORRIS, J. T., ROBINO, C. V., HIRSCHFELD, D. A., et al., "Effects of Laser Parameters on Porosity Formation: Investigating Millimeter Scale Continuous Wave Nd:YAG Laser Welds", Welding Journal, v. 90, pp. 198-203, 2011

[21] CHEN, G., MEI, L., ZHANG, M., et al., "Research on key influence factors of laser overlap welding of automobile body galvanized steel", Optics \& Laser Technology, v. 45, pp. 726-733, Feb 2013

[22] EVANS, G. M., BAILEY, N., Metallurgy of basic weld metal, 1 ed., Cambridge, England, Abington Publishing, 1997 